\title{
Factors influencing decision regret regarding placement of a PEG among substitute decision-makers of older persons in Japan: a prospective study
}

Yumiko Kuraoka* and Kazuhiro Nakayama

\begin{abstract}
Background: A tube feeding decision aid designed at the Ottawa Health Research Institute was specifically created for substitute decision-makers who must decide whether to allow placement of a percutaneous endoscopic gastrostomy (PEG) tube in a cognitively impaired older person. We developed a Japanese version and found that the decision aid promoted the decision-making process of substitute decision-makers to decrease decisional conflict and increase knowledge. However, the factors that influence decision regret among substitute decision-makers were not measured after the decision was made. The objective of this study was to explore the factors that influence decision regret among substitute decision-makers 6 months after using a decision aid for PEG placement.
\end{abstract}

Methods: In this prospective study, participants comprised substitute decision-makers for 45 inpatients aged 65 years and older who were being considered for placement of a PEG tube in hospitals, nursing homes and patients' homes in Japan. The Decisional Conflict Scale (DCS) was used to evaluate decisional conflict among substitute decision-makers immediately after deciding whether to introduce tube feeding and the Decision Regret Scale (DRS) was used to evaluate decisional regret among substitute decision-makers 6 months after they made their decision. Normalized scores were evaluated and analysis of variance was used to compare groups.

Results: The results of the multiple regression analysis suggest that PEG placement $(P<.01)$ and decision conflict $(P<.001)$ are explanatory factors of decision regret regarding placement of a PEG among substitute decision-makers.

Conclusions: PEG placement and decision conflict immediately after deciding whether to allow PEG placement have an influence on decision regret among substitute decision-makers after 6 months.

Keywords: Decision regret, Decision conflict, Decision-making, Feeding tube, Older person

\section{Background}

The American Geriatrics Society issued a position statement about feeding tubes in those with advanced dementia in 2014 that included the following statement: "Feeding tubes are not recommended for older adults with advanced dementia. Hand feeding is at least as good as tube feeding for the outcomes of death, aspiration pneumonia, functional status, and comfort. Tube feeding is associated with agitation, greater use of physical

\footnotetext{
* Correspondence: y-noda@slcn.ac.jp

Graduate School of Nursing Science, St. Luke's International University, 10-1

Akashi-cho, Chuo-ku, Tokyo 104-0044, Japan
}

and chemical restraints, greater healthcare use due to tube-related complications, and development of new pressure ulcers" [1].

In Japan, the percentage of the population aged 65 years and over was $26.7 \%$ in 2015 [2], and the number of those with disturbance of swallowing is increasing. Many patients receive percutaneous endoscopic gastrostomy (PEG) and a tube feeding for artificial nutrition. A private-sector research institution in Japan [3] reported that PEG kit sales were above 100,000 units in 2005, and more than 700,000 people exchanged PEG kits in 2010. Surveys of the survival of older patients after PEG 
in Western countries found that $55 \%$ and $45 \%$ of patients survived more than 6 months and 1 year, respectively $[4,5]$. On the other hand, in Japan, a survey of survival among 931 older patients after PEG found that 75\% and $66 \%$ of patients survived more than 6 months and 1 year, and $50 \%$ and $25 \%$ of those who had feeding tubes survived 753 and 1647 days, respectively [6]. The survival rate of older patients after PEG in Japan is higher than in Western countries, and we think that is the reason why PEG placement is more common in Japan.

Few studies have examined decision-making for the use of feeding tubes [7-10]. Caregivers report little conversation about feeding tube decisions with medical staff (more than half of caregivers report no conversation or conversations of less than $15 \mathrm{~min}$ ), and at times, families feel pressured to use feeding tubes [7]. Another study in Japan showed that many patients are not involved in the decision-making process because of cognitive problems, and most patients do not discuss their intentions regarding tube feeding with their family in advance; therefore, family members make all of the decisions with the support of physicians. In that study, physicians provided positive recommendations more frequently for the tube-feeding group $(19 / 23,83 \%)$ than for the withholding group $(5 / 12,42 \%)(P=.01)$ [8].

A previous study in Japan identified five factors that influence Japanese physicians' decision to provide artificial hydration and nutrition (AHN) through PEG tubes: (1) the national health insurance system that allows elderly patients to become long-term hospital in-patients; (2) legal barriers with regard to limiting treatment, including the risk of prosecution; (3) emotional barriers, especially abhorrence of death by "starvation"; (4) cultural values that promote family-oriented end-of-life decision making; and (5) reimbursement-related factors involved in the choice of PEG [9].

A study of 4506 physicians who were members of the Japan Geriatrics Society found that only 6\% responded that they did not have difficulty determining whether AHN should be introduced, and half responded that an ethical problem occurs when deciding to withhold AHN [10]. In Japan, since families and physicians often recognize cognitively impaired older patients to be unable to make their own decisions, physicians are generally relied upon for decisions involving AHN. A study on the perception of families of dementia patients who received placement of a PEG reported that $26.7 \%$ of 33 families wavered in their judgment of PEG between "good" and "not good", and 13.3\% felt it was "not good" [11]. Since older patients with cognitive impairment often cannot make choices for themselves, family members act as substitute decision-makers. The decision of family members often involves many conflicting facts and emotions and creates a heavy mental burden.
A tube feeding decision aid designed at the Ottawa Health Research Institute was specifically created for substitute decision-makers who must decide whether to allow placement of a PEG tube in a cognitively impaired older person who is unable to eat independently [12]. The decision aid contains information about the following topics: common causes of eating and swallowing problems in older persons with cognitive impairment; technical considerations regarding the placement of and how to use PEG tubes; the principles and process of substitute decision-making; the risks and benefits of tube feeding; the option of supportive care; and some considerations regarding future discontinuation of PEG tube feeding if the substitute decision-maker opts for an intervention. We developed and evaluated the Japanese version of this decision aid in a previous study with a before-and-after test design [13] (Additional file 1). In that study, substitute decision-makers showed significantly increased knowledge $(P<.001)$ and decreased decisional conflict $(P<.01)$ regarding long-term tube feeding after using the decision aid.

Decision aids for tube feeding in older patients have been shown to improve the quality of decisionmaking for substitute decision-makers. However, our previous study [13] focused on decision-making when they decided whether to introduce tube feeding and the factors that influence decision regret among substitute decision-makers were not measured after the fact. Therefore, the objective of this study was to explore the factors that influence decision regret among substitute decision-makers 6 months after using a decision aid for PEG placement.

\section{Methods}

\section{Recruitment and data collection}

Participants were recruited from all over Japan between January 2014 and August 2014. Participants were substitute decision-makers who were at the point of deciding whether to place a PEG tube in older family members and who obtained a decision aid that we developed. The decision aids were specifically prepared for substitute decision-makers charged with deciding whether to allow the placement of PEG tubes in cognitively impaired individuals aged $\geq 65$ years and judged as unable to eat independently. We developed a website [14] that not only introduced the decision aid, but also enabled participants to request the decision aid. Decision aids could alternatively be obtained from medical staff.

When substitute decision-makers requested a decision aid from the website, we mailed them the decision aid, information about the present study and the initial questionnaire. Substitute decision-makers who obtained the decision aid from medical staff were also 
given information about the study and a request to participate. We then mailed the initial questionnaire to those who consented to participate in this study. We asked substitute decision-makers to complete and return the initial questionnaire immediately after they decided whether or not to place a PEG tube. Returning the initial questionnaire was taken as providing consent to participate in the study. After 6 months, we mailed a second questionnaire to substitute decision-makers who returned the initial questionnaire. Those who returned completed the initial and second questionnaires were taken as study participants. (Fig. 1).

\section{Questionnaires}

The questionnaires consisted of items on decisional conflict and decisional regret. Conflict with decision- making was assessed using the Decisional Conflict Scale (DCS) [15], which was translated into Japanese with the developer's consent with reference to the Japanese version for women considering prenatal testing [16]. Based on the responses to 16 questions, this scale evaluates five domains of decisional conflict: (1) certainty regarding choices; (2) feeling informed; (3) feeling clear about values; (4) feeling supported in decision-making; and (5) quality of the decision. Each question was rated on a 5-point Likert scale, with higher values representing greater decisional conflict. The DCS can be evaluated both before and after decision-making and was included only in the initial questionnaire in this study. The validity and reliability of the Japanese version of the DCS have been confirmed [17].

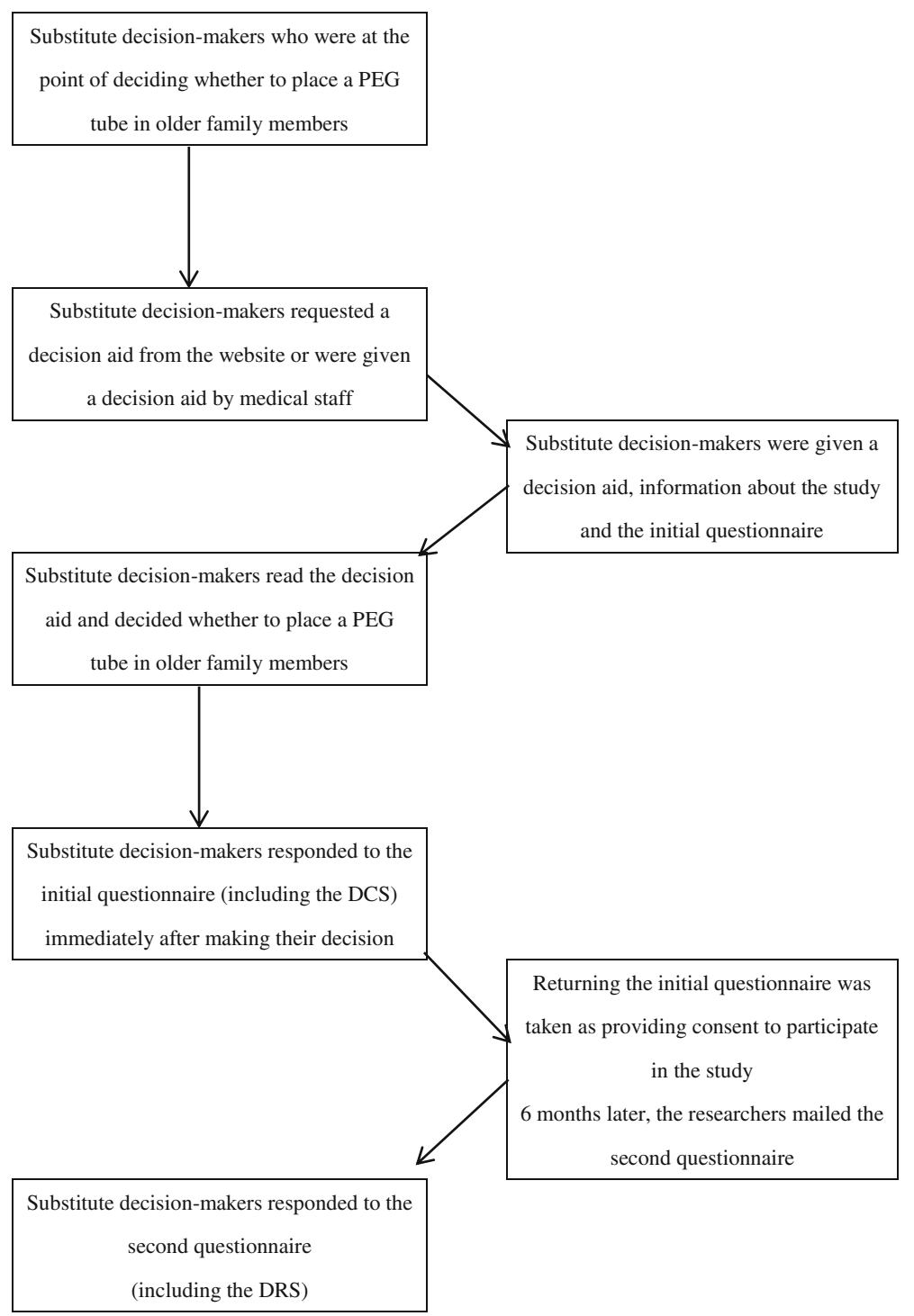

Fig. 1 Recruitment and data collection 
Decisional regret was measured using the Decisional Regret Scale (DRS) [18], which measures distress or remorse after a health care decision and reflection on a specific past decision. The DRS includes a five-item scale and responses to each item were given on a 5-point Likert scale ranging from 1 ("I strongly agree") to 5 ("I strongly disagree"), with higher values representing greater decisional regret. The validity and reliability of the Japanese version of the DRS have been confirmed [19].

\section{Study design}

A prospective study was conducted to evaluate the DCS and DRS. Substitute decision-makers completed the initial questionnaire, which included the DCS, immediately after making their decision. The substitute decisionmakers were contacted again 6 months after the initial contact and asked to respond to a second questionnaire that included the DRS.

\section{Statistical analysis}

Normalized scores were evaluated and multiple regression analysis was used to identify explanatory factors that influence decision regret among substitute decisionmakers. We set patient characteristics (gender, survival, PEG placement or not, patient can convey own wishes or not), substitute decision-maker characteristics (age, relationship to the patient), physician's recommendation for the patient to receive PEG placement or to withhold PEG, and substitute decision-makers' decision conflict as independent variables. We set the DRS score as the dependent variable. The independent variables and dependent variable were set with reference to previous studies $[7,8,10,13]$.

\section{Results}

\section{Enrollment}

One hundred fifty two substitute decision-makers obtained the decision aid from the website and one substitute decision-maker obtained the decision aid from medical staff in charge of the patient. All decision-makers were approached by the study team. Of these, a total of 45 (29.4\%) substitute decision-makers agreed to participate in the study. Forty-five (100\%) of 45 substitute decisionmakers responded to the follow-up questionnaire.

\section{Patient and substitute decision-maker characteristics}

Table 1 shows the characteristics of the patients enrolled in the study. The mean age \pm standard deviation (SD) of the patients was $84.1 \pm 8.3$ years; 24 were female. The diagnostic indications for PEG placement included aspiration pneumonia $(n=17)$, dementia $(n=11)$, cerebral infarction $(n=11)$, Parkinson disease $(n=2)$, depression $(n=2)$, pneumonia $(n=2)$, intractable neurological diseases $(n=2)$, cancer $(n=1)$ and other disease $(n=13)$. The settings of the patients were an acute care hospital $(n=16)$, mixed care hospital $(n=10)$, longterm care hospital $(n=8)$, nursing home $(n=8)$, and patient's home $(n=3)$. The level of physical activity of the patients was bed-bound but cannot toss and turn $(n=24)$, bed-bound but can toss and turn $(n=10)$, use a wheelchair mainly $(n=4)$, ambulant $(n=4)$, and other level $(n=3)$. The communicative ability of the patients was cannot communicate sometimes $(n=22)$, cannot communicate at all $(n=16)$, and can easily communicate $(n=7)$.

Twelve of 45 patients were able to convey their wishes. Seven of these 12 patients wished to receive PEG and five wished to not receive PEG. Of these, seven of seven substitute decision-makers decided for PEG placement and five of five substitute decision-makers decided to withhold PEG, respectively; therefore, the decisions of all 12 of these substitute decision-makers were in accordance with the wishes of the patient.

The mean age \pm SD of the substitute decision-makers was $62.1 \pm 10.5$ years; 25 were male. Substitute decisionmakers had the following relationships to the patients: child $(n=24)$, spouse $(n=11)$, son/daughter-in-law $(n=5)$, nephew/niece $(n=1)$, brother/sister-in-law $(n=1)$, and other relative $(n=3)$. Forty-four of 45 substitute decision-makers found the website that we developed and requested that we mail a decision aid to them. One of 45 substitute decision-makers was handed a decision aid by a medical staff member. Forty-three of 45 substitute decision-makers read all the contents of the decision aid. One of 45 substitute decision-makers read some of the contents of the decision aid. One of 45 substitute decision-makers did not read the decision aid. Eleven of 45 substitute decision-makers consulted with the physician in charge of the patient regarding the decision aid. Six of 45 substitute decision-makers consulted with a care manager. Five of 45 substitute decisionmakers consulted with a nurse. Two of 45 substitute decision-makers consulted with a physician not in charge of the patient. One of 45 substitute decisionmakers consulted with a social worker. Twenty-three of 45 substitute decision-makers consulted with nobody.

\section{Physician's recommendation}

We asked substitute decision-makers whether the physician recommended for the patient to receive PEG placement, to not receive PEG placement, or made no recommendation. Twenty-five substitute decision-makers answered that the physician recommended PEG placement, five substitute decision-makers answered that the physician did not recommend PEG placement, and 15 substitute decision-makers answered that the physician did not make any recommendation. Physicians provided 
Table 1 Characteristics of patients and substitute decisionmakers $(n=45)$

\begin{tabular}{|c|c|c|c|}
\hline \multicolumn{4}{|l|}{ Patients } \\
\hline \multicolumn{2}{|l|}{ Mean age (years) } & \multicolumn{2}{|l|}{$84.1 \pm 8.3$} \\
\hline \multicolumn{2}{|l|}{ Female } & 24 & $53.3 \%$ \\
\hline \multirow[t]{10}{*}{ Diagnosis } & Aspiration pneumonia & 17 & \\
\hline & Dementia & 11 & \\
\hline & Cerebral infarction & 11 & \\
\hline & Parkinson disease & 2 & \\
\hline & Depression & 2 & \\
\hline & Pneumonia & 2 & \\
\hline & $\begin{array}{l}\text { Intractable } \\
\text { neurological diseases }\end{array}$ & 2 & \\
\hline & Cancer & 1 & \\
\hline & Other disease & 13 & \\
\hline & $\begin{array}{l}\text { (multiple answers } \\
\text { allowed) }\end{array}$ & & \\
\hline \multirow[t]{5}{*}{ Setting } & Acute care hospital & 16 & $35.6 \%$ \\
\hline & $\begin{array}{l}\text { Long-term care } \\
\text { hospital }\end{array}$ & 8 & $17.8 \%$ \\
\hline & Mixed care hospital & 10 & $22.2 \%$ \\
\hline & Nursing home & 8 & $17.7 \%$ \\
\hline & Patients' home & 3 & $6.7 \%$ \\
\hline \multirow[t]{5}{*}{ Physical activity } & $\begin{array}{l}\text { Bed-bound (cannot } \\
\text { toss and turn) }\end{array}$ & 24 & $53.3 \%$ \\
\hline & $\begin{array}{l}\text { Bed-bound (can toss } \\
\text { and turn) }\end{array}$ & 10 & $22.2 \%$ \\
\hline & $\begin{array}{l}\text { Primarily use a } \\
\text { wheelchair }\end{array}$ & 4 & $8.9 \%$ \\
\hline & Ambulant & 4 & $8.9 \%$ \\
\hline & Other level & 3 & $6.7 \%$ \\
\hline \multirow[t]{3}{*}{ Communicative ability } & $\begin{array}{l}\text { Can easily } \\
\text { communicate }\end{array}$ & 7 & $15.6 \%$ \\
\hline & $\begin{array}{l}\text { Cannot sometimes } \\
\text { communicate }\end{array}$ & 22 & $48.9 \%$ \\
\hline & $\begin{array}{l}\text { Cannot communicate } \\
\text { at all }\end{array}$ & 16 & $35.6 \%$ \\
\hline \multirow{3}{*}{$\begin{array}{l}\text { Ability to convey } \\
\text { wishes about PEG } \\
\text { placement }\end{array}$} & $\begin{array}{l}\text { Able to convey } \\
\text { own wishes }\end{array}$ & 12 & $26.7 \%$ \\
\hline & $\begin{array}{l}\text { Unable to convey } \\
\text { own wishes }\end{array}$ & 28 & $62.2 \%$ \\
\hline & Neither & 5 & $11.1 \%$ \\
\hline \multirow{2}{*}{$\begin{array}{l}\text { Wishes regarding } \\
\text { PEG placement }\end{array}$} & Place PEG & $7 / 12$ & $58.3 \%$ \\
\hline & Withhold PEG & $5 / 12$ & $41.7 \%$ \\
\hline \multicolumn{4}{|c|}{ Substitute decision-makers } \\
\hline \multicolumn{2}{|l|}{ Mean age (years) } & \multicolumn{2}{|l|}{$62.1 \pm 10.5$} \\
\hline Male & & 25 & $55.6 \%$ \\
\hline \multirow{3}{*}{$\begin{array}{l}\text { Relationship to } \\
\text { the patient }\end{array}$} & Child & 24 & $53.3 \%$ \\
\hline & Spouse & 11 & $24.4 \%$ \\
\hline & Son/daughter-in-law & 5 & $11.1 \%$ \\
\hline
\end{tabular}

Table 1 Characteristics of patients and substitute decisionmakers ( $n=45)$ (Continued)

\begin{tabular}{llll}
\hline & Nephew/niece & 1 & $2.2 \%$ \\
& Brother/sister-in-law & 1 & $2.2 \%$ \\
How decision & Other relative & 3 & $6.7 \%$ \\
aid was obtained & Website & 44 & $97.8 \%$ \\
Read the contents & Medical staff & 1 & $2.2 \%$ \\
of the decision aid & All & 43 & $95.6 \%$ \\
& Some & 1 & $2.2 \%$ \\
Consulted with & None & 1 & $2.2 \%$ \\
& Physician in charge of & 11 & \\
& the patient & & \\
& Care manager & 6 & \\
& Nurse & 5 & \\
& Physician not in & 2 & \\
charge of the patient & & \\
& Social worker & 1 & \\
& Nobody (multiple & 23 & \\
answers allowed) & & \\
Decision in accordance with & PEG placed & $7 / 7$ & $100 \%$ \\
the patient's wishes & PEG withheld & $5 / 5$ & $100 \%$ \\
\hline
\end{tabular}

positive recommendations more frequently for the PEG placement group $(18 / 20,90 \%)$ than for the withholding group $(7 / 25,28 \%)(P<.001)$.

\section{Decisions and functional status}

Twenty (44.4\%) of 45 substitute decision-makers had decided to use PEG placement when they completed the initial questionnaire, and $20(44.4 \%)$ of these patients received PEG placement. Twenty-five (55.6\%) of 45 substitute decision-makers had decided not to use PEG placement when they completed the initial questionnaire, and $23(51.1 \%)$ of these patients did not receive PEG placement. During the follow-up period, 15 (75\%) of the 20 patients who received PEG placement survived, and $16(69.6 \%)$ of the 23 patients who did not receive PEG placement survived (Fig. 2).

\section{Multiple regression analysis}

The results of the multiple regression analysis suggest that PEG placement $(P<.01)$ and decision conflict $(P<.001)$ of substitute decision-makers are explanatory factors of decision regret among substitute decision-makers (Table 2).

\section{Discussion}

In this study, only $24.4 \%$ of the patients suffered from dementia and $64.5 \%$ of the patients could easily communicate or could communicate most of the time. The level of dementia of the patients who participated in this study varied. Of the patients who received PEG placement, 75\% survived more than 6 months. Our finding 


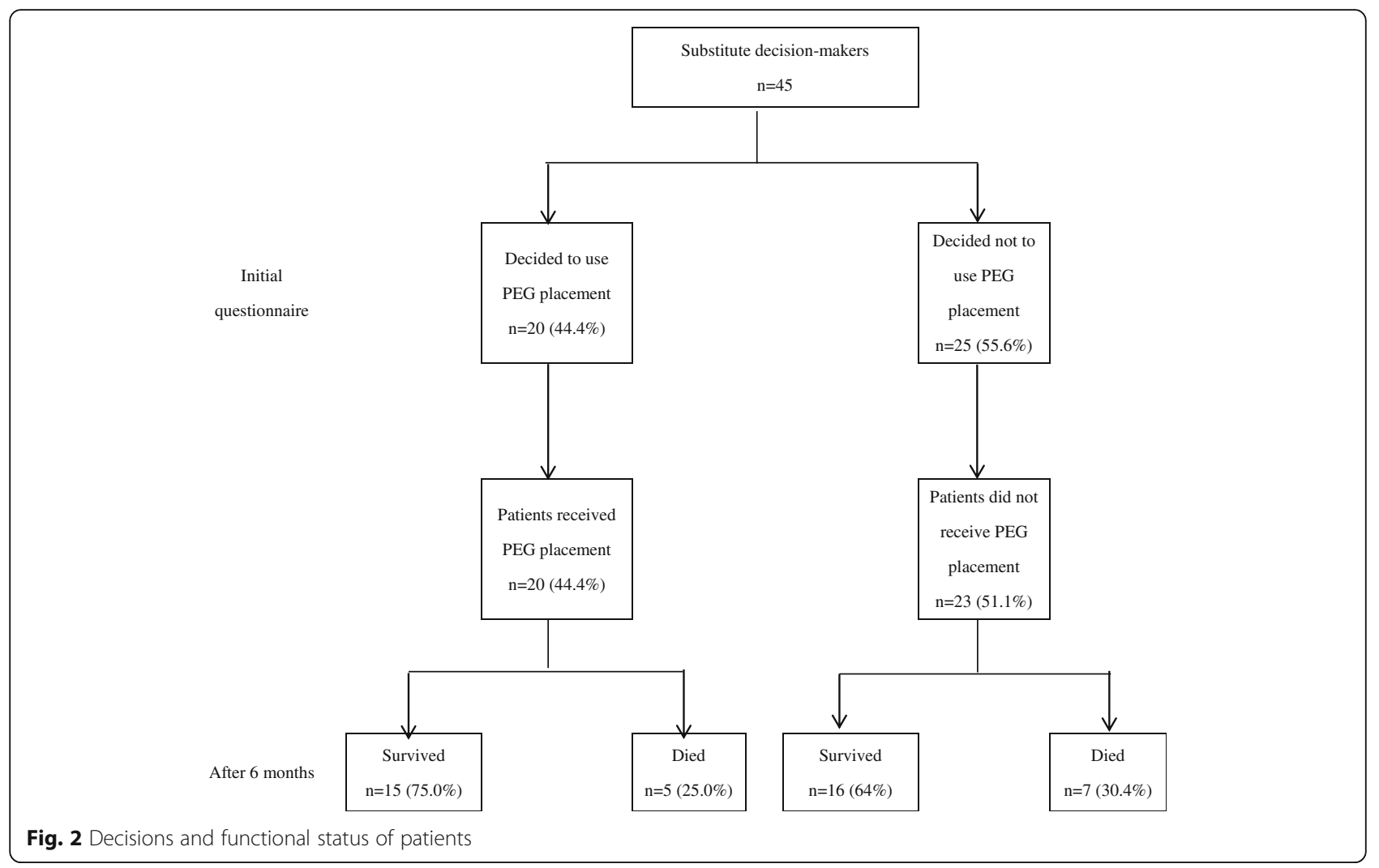

for mortality was similar to the results of a previous survey of survival of older patients after PEG placement in Japan [6]. Some patients in that study had dementia (15\% had severe dementia, 3\% had mild dementia, $14 \%$ had other types of dementia), but the prognosis did not differ between this study and that study [6].

The results of the present study showed physicians provided positive recommendations more frequently for the PEG placement group than for the withholding group $(P<.001)$. We believe it is possible that substitute decision-makers might have decided to use PEG placement because they felt pressure from the physician. The American Geriatrics Society stated that, "Institutions such as hospitals, nursing homes, and other care settings should promote choice, endorse shared and informed decision-making, and honor individuals' preferences regarding tube feeding. They should not impose obligations or exert pressure on individuals, or providers to institute tube feeding" [1]. We think it is important to educate medical providers about appropriate end-of-life care for old people for example, the introduction of feeding tubes is not typically performed to prolong life, prevent aspiration pneumonia, heal pressure ulcers, or improve quality of life [20-22].

The results of the present study showed that decision regret among substitute decision-makers of patients who received PEG placement was significantly higher than that of those who did not receive PEG placement. The reason why many substitute decision-makers choose PEG placement is because it is difficult to accept the patient's death by starvation [23, 24]. A previous study in Japan [23] showed substitute decision-makers worried about whether PEG placement was good for the patients; the results of the present study ware similar. It is important that medical staff support substitute decisionmakers carefully if they decide to use PEG placement, and substitute decision-makers should receive ongoing education about the natural senile process and the natural progression of dementia, which includes eating difficulties.

Substitute decision-makers who had higher decision conflict when they chose or withheld PEG placement also had higher decision regret after 6 months. Endo et al. [25] proposed that medical staff and family should confirm the patient's intentions in the early stages of dementia. We believe the decision conflict of substitute decision-makers will decrease if they can make decisions based on the patient's intentions. In this study, 12 of 45 (26.7\%) patients were able to convey their own wishes and their substitute decision-makers could act in accordance with their wishes. We believe if patients can convey their own wishes, the patient and family can share decision-making. On the other hand, although 29 of 45 (64.5\%) patients could easily communicate or could communicate most of them, substitute decision-makers 
Table 2 Results of the regression analysis: final models

\begin{tabular}{|c|c|c|c|c|c|c|c|}
\hline \multirow[b]{2}{*}{ Variable } & \multirow[b]{2}{*}{ Mean } & \multicolumn{3}{|c|}{ Bivariate regression analysis } & \multicolumn{3}{|c|}{ Multiple regression analysis } \\
\hline & & $\beta$ & $\mathrm{F}$ & P & $\beta$ & $\mathrm{F}$ & P \\
\hline \multicolumn{8}{|c|}{ Dependent variable: Decision regret of substitute decision-maker } \\
\hline \multicolumn{8}{|l|}{ Patients } \\
\hline Gender/male & 33.86 & -0.209 & 1.866 & 0.179 & 0.171 & 0.521 & 0.476 \\
\hline Gender/female & 30.42 & & & & & & \\
\hline Survival/survived & 30.83 & 0.034 & 0.048 & 0.827 & -0.207 & 0.547 & 0.465 \\
\hline Survival/died & 34.05 & & & & & & \\
\hline PEG placed & 38.19 & -0.423 & 8.732 & 0.005 & 0.796 & 9.925 & 0.004 \\
\hline PEG withheld & 24.82 & & & & & & \\
\hline Patient can convey own wishes & 25.00 & -0.427 & 1.514 & 0.226 & -0.411 & 1.873 & 0.182 \\
\hline Patient cannot convey own wishes & 33.13 & & & & & & \\
\hline \multicolumn{8}{|l|}{ Substitute decision-makers } \\
\hline Gender/male & 30.44 & 0.209 & 1.866 & 0.179 & -0.071 & 0.068 & 0.797 \\
\hline Gender/female & 33.61 & & & & & & \\
\hline Age & & 0.010 & 0.004 & 0.948 & 0.015 & 1.719 & 0.200 \\
\hline Relationship/child of patient & 30.40 & -0.099 & 0.409 & 0.526 & 0.126 & 0.237 & 0.630 \\
\hline Relationship/not child of patient & 34.16 & & & & & & \\
\hline \multicolumn{8}{|l|}{ Consulted with } \\
\hline Medical staff & 35.81 & 0.132 & 0.695 & 0.409 & -0.166 & 0.215 & 0.646 \\
\hline Nobody & 28.38 & & & & & & \\
\hline \multicolumn{8}{|l|}{ Physician's recommendation } \\
\hline Either withhold or place PEG & 35.20 & -0.252 & 2.787 & 0.103 & 0.194 & 0.424 & 0.520 \\
\hline No recommendation & 24.10 & & & & & & \\
\hline Decision conflict of substitute decision-makers & & 0.583 & 21.091 & $<0.001$ & 0.625 & 21.945 & $<0.001$ \\
\hline
\end{tabular}

Gender: 1 = male, 2 = female

Survival: $1=$ survived, $2=$ died

PEG: 1 = PEG placed, 2 = withheld

Patient's wishes: 1 = patient can convey own wishes, 2 = patient cannot convey own wishes

Relationship: 1 = child of patient, $2=$ not child of patient

Consulted with: 1 = medical staff, 2 = nobody

Physician's recommendation: 1 = either withhold or place PEG, 2 = no recommendation

indicated that only 12 of $45(26.7 \%)$ patients could convey their own wishes. It is possible that family and medical staff might not make enough of an effort to determine the patient's wishes. Family and medical staff should support patients in making their own decisions and make an effort to hear the patient's wishes when they are deciding whether to use or withhold PEG placement.

We found that $97.8 \%$ of substitute decision-makers obtained the decision aid by themselves through the website and $95.6 \%$ read all the contents of the decision aid. We think that most substitute decision-makers in the present study had high health literacy. Although a previous study showed that a decision aid for feeding options in advanced dementia improved the frequency of substitute decision-makers' communication with medical providers [26], 51.1\% of substitute decision-makers in the present study did not consult with medical staff regarding the decision aid. This seems partly because the Japanese cultural environment supports physicians' paternalism and substitute decision-makers hesitate to approach physicians. It is important that substitute decision-makers communicate with medical providers regarding the decision aid to discuss the probable wishes of the patient and the best choice for that specific patient, especially when the patient's wishes are unknown.

The present research has some of important limitations. First, because the number of participants was small, generalization of the results is limited. The number of participants should be increased to analyze the explanatory factors of decision regret among substitute decisionmakers in more detail.

Second, the elderly individuals investigated in this study had varying levels of cognitive function, as there were cases in which patients were able and unable to convey their wishes regarding PEG placement. Therefore, it can be inferred that there were various cases, 
from those in which families made decisions by respecting the wishes that were clearly indicated by the patients, to those in which the wishes of the patients were unclear and families made decisions by surmising the patients' wishes.

Third, the subjects of this study were limited to substitute decision-makers who used our decision aid for decisionmaking; we did not compare decision regret among substitute decision-makers who made decisions without using the decision aid. It is necessary to compare decision regret of both types of substitute decision-makers to determine the efficacy of this decision aid over the long term.

Fourth, the most frequent settings of patients in the present study were hospitals and nursing homes. The setting of medical treatment in Japan is increasingly shifting from hospitals to the home. Thus, it is also necessary to further evaluate decision regret for patients receiving care at home.

\section{Conclusions}

The present study showed that PEG placement $(P<.01)$ and decision conflict $(P<.001)$ of substitute decisionmakers immediately after deciding whether to use PEG placement in a cognitively impaired older person have an influence on decision regret after 6 months. Further research comparing substitute decision-makers who made decisions about placement of a PEG both with and without the decision aid is needed to compare decision regret among substitute decision-makers and to analyze the long-term efficacy of this decision aid.

\section{Additional file}

Additional file 1 English version of decisional aid. (PDF 9372 kb)

\section{Abbreviations}

AHN: artificial hydration and nutrition; DCS: Decisional conflict scale DRS: Decision regret scale; PEG: percutaneous endoscopic gastrostomy

\section{Acknowledgments}

The authors would like to thank the 45 substitute decision-makers who took part in this research.

\section{Funding}

This work was supported by MEXT KAKENHI (Grant Number 25862123). The funding source had no role in the design or conduct of the study; the collection, management, analysis, or interpretation of the data, or the preparation, review, or approval of the manuscript.

\section{Availability of data and materials}

The datasets used and analyzed during the current study are available from the corresponding author on reasonable request.

\section{Authors' contributions}

YK was involved in all aspects of the research, including study design, subject recruitment, data analysis, and manuscript preparation. KN's role in the study included assistance with study design, supervision of data collection, data analysis, and preparation of the manuscript. YK and KN have read and approved the manuscript.

\section{Ethics approval and consent to participate}

This study complied with the Declaration of Helsinki and was approved by the Research Ethics Committee of St. Luke's International University (approval number: 13-064). We informed participants about this research through information attached to the questionnaires. Returning a completed questionnaire was taken as providing consent to participate.

Consent for publication

Not applicable.

\section{Competing interests}

The authors declare that they have no competing interests.

\section{Publisher's Note}

Springer Nature remains neutral with regard to jurisdictional claims in published maps and institutional affiliations.

Received: 20 January 2017 Accepted: 22 June 2017

Published online: 28 June 2017

\section{References}

1. American Geriatric Society Ethics Committee and Clinical Practice and Models of Care Committee. American geriatrics society feeding tubes in advanced dementia position statement. Journal of American Geriatrics Society. 2014;62:1590-3.

2. Cabinet Office, Government of Japan. Aged society white paper 2015. http://www.mhlw.go.jp/wp/hakusyo/kousei/16-1/dl/gaiyou.pdf. Accessed 11 Jan 2017.

3. Yano Research Institute. Do you perform PEG? Chunichi Shimbun, Jan. 4, 2011.

4. Rabenek L, Wray NP, Petersen NJ. Long-term outcomes of patients receiving percutaneous endoscopic gastrostomy tubes. J Gen Intern Med. 1996;11:287-93.

5. Taylor CA, Larson DE, Ballard DJ, Bergstrom LR, Silverstein MD, Zinsmeister $A R$, et al. Predictors of outcome after percutaneous endoscopic gastrostomy: A community-based study. Mayo Clin Proc. 1992;67:1042-9.

6. Suzuki Y, Tames S, Murakami A, Taira A, Mizuhara A, Horiguchi A, et al. Survival of geriatric patients after PEG in Japan. World J Gatroenterol. 2010; 16:5084-91.

7. Teno JM, Michell SL, Kuo SK, Gozalo PL, Phodes RL, Lima JC, et al. Decisionmaking and outcomes of feeding tube insertion: A five-state study. J Am Geriatr Soc. 2011;59:881-6.

8. Kuroda $Y$, Kuroda R. Factors affecting the decision to provide artificial nutrition for elderly adults with oral intake difficulty. J Am Geriatr Soc 2013;61:1835-6

9. Aita K. Survey of Japanese geriatricians on their practices and attitude towards artificial nutrition and hydration for patients with end-stage dementia. Nippon Ronen Igakkai Zasshi. 2012:49:71-4.

10. Japan Geriatrics Society. Guidelines for decision-making process in elderly care focusing on indications of artificial hydration and nutrition. 2012. http://www.jpn-geriat-soc.or.jp/info/topics/pdf/jgs_ahn_gl_2012.pdf. Accessed 11 Jan 2017.

11. Yoshino J, Sakoda A, Kawane $H$. The present condition and the subject of decision-making for the PEG of a cognitively impaired elderly person at home. In: Proceedings of the $27^{\text {th }}$ Academic Conference, Japan Academy of Nursing Science: 7-8 December 2007. Tokyo: Japan Academy of Nursing Science; 2007. p. 131.

12. Ottawa Health Research Institute. Making Choices: Long Term Feeding Tube Placement in Elderly Patients 2001. http://decisionaid.ohri.ca/docs/Tube_ Feeding_DA/PDF/TubeFeeding.pdf. Accessed 11 Jan 2016.

13. Kuraoka Y, Nakayama K. A decision aid regarding long-term tube feeding targeting substitute decision makers of cognitively impaired older persons in Japan: a small-scale before-and-after study. BMC Geriatr. 2014;14(16):1-7.

14. Kuraoka Y. A decision aid regarding long-term tube feeding targeting substitute decision makers of older persons in Japan 2013. http:// irouishikettei.jp/

15. O'Connor A. Validation of a decisional conflict scale. Med Dec Making 1995;15:25-30.

16. Arimori N. Randomized controlled trial of decision aids for women considering prenatal testing: The effect of the Ottawa Personal Decision Guide on decisional conflict. Jpn J Nurs Sci. 2006;3:119-30. 
17. Arimori N. Examination of the validity and reliability of Japanese version DCS for women considering prenatal testing. Proceedings of the 5th annual conference of the Japan Association for Research on Testing. 2007:208-9.

18. Brehaut JC, O'Connor AM, Wood TJ, Hack TF, Siminoff L, Gordeon E, et al. Validation of a decision regret scale. Med Decis Mak. 2003;23(4):281-92.

19. Tanno K, Bito Y, Isobe $Y$, Takagi $Y$. Validation of a Japanese version of the Decision Regret Scale. J Nurs Meas. 2016;24(1):44-54.

20. Finucane TE, Chiristmas G, Travis K. Tube feeding in patients with advanced dementia: A review of the evidence. JAMA. 1999;282:1365-70.

21. Gillick MR. Rethinking the role of tube feeding in patients with advanced dementia. N Engl J Med. 2000;342:206-10.

22. Uemura K. Characteristics of end-of-life care for elderly patients [in Japanese]. In: Iguchi A, editor. New geriatrics. Nagoya: Nagoya University Press; 2000. p. 302-5.

23. Aiba K, Koizumi M. Psychological process of family members as substitute decision makers selecting gastrostomy for elderly patients with advanced dementia. JAGN. 2011;16:75-84.

24. Yagi T, Kitamura S. Food intake and nutrition in advanced dementia [in Japanese]. Japanese Journal of Geriatrics Psychiatry. 2011;22(12):1391-7.

25. Endo H, Miura H, Satake D. The way medical for the end of life in dementia [in Japanese]. Diagnosis and Treatment. 2011;99(3):523-5.

26. Hanson LC, Carey TS, Caprio AJ, Lee TJ, Ersek M, Garrett J, et al. Improving decision making for feeding options in advanced dementia: a randomized, controlled trial. J Am Geriatr Soc. 2011;59:2009-16.

\section{Submit your next manuscript to BioMed Central} and we will help you at every step:

- We accept pre-submission inquiries

- Our selector tool helps you to find the most relevant journal

- We provide round the clock customer support

- Convenient online submission

- Thorough peer review

- Inclusion in PubMed and all major indexing services

- Maximum visibility for your research

Submit your manuscript at www.biomedcentral.com/submit 